\title{
Microseismics for cavern stability evaluation of a powerhouse structure after excavation
}

\author{
Vikalp Kumar and Sivakumar Cherukuri \\ Microseismics \& Engineering Seismology \\ National Institute of Rock Mechanics \\ Bengaluru, India \\ vikalpk@gmail.com
}

\author{
N Gopalakrishnan \\ Geology Department, \\ National Thermal Power Corporation Ltd \\ Joshimath, India
}

\begin{abstract}
The powerhouse of Tapovan Vishnugad Hydropower project (TVHPP) of NTPC is located in the tail of the Great Himalaya range in the Chamoli district, Uttrakhand and is located at $+300 \mathrm{~m}$ depth having adverse geological conditions. The project area is situated near the northern side of MCT around $2.0 \mathrm{Km}$ and lies in the seismic zone $\mathrm{V}$ of India. This site encounters a number of rockburst during and after excavation at various places which may be due to the stress redistribution.This paper discusses the designing and primary application of microseismic monitoring technique after post excavation in rocks. A microseismic network has been installed at the powerhouse site of a hydropower project to study the strata conditions and redistribution of stresses after excavation. This paper discusses the microseismic network design based on the existing geological reports, rockburst history, feasibility of drilling and many other parameters. The monitoring system consists of a three dimensional array of sensors, data acquisition unit, cable layout, and an underground laboratory equipped with communication equipment, data acquisition, processing and interpretation software.The primary monitoring period identifies the potential failure zone of rock fracture in the powerhouse by studying different source parameters and provides the information about the stability of the structure.
\end{abstract}

Keywords-Microseismics, rockburst, TVHPP, cavern stability

\section{INTRODUCTION}

The stress state is disturbed as excavation in and around a rockmass takes place that results in the redistribution of the local stress. If the rock mass is of high strength brittle type, it increases the risk of violent failures. Such violent failures are a safety risk for mine and civil engineering personnel. During the past few decades, large number of violent failures have been observed in deeper mining and in Middle-Great Himalaya region. Such types of failures are usually known as rockburst.

Bennett and McLaughlin [1] defined rockbursts, as "any type of stress-release phenomenon which has been induced by mining activity and which results in emission of seismic signals".Rockburst has been a major problem in deep underground mines [2] and excavations in geologically younger region such as Himalaya. A number of rock bursts occur in underground caverns in Indian Himalayan belt and China hydropower projects [3]during and after the excavation.

Tapovan Vishnugad Hydro Power Project (TVHPP) of $520 \mathrm{MW}$ in Chamoli, Uttrakhand is a "Run off the River Scheme" on river Dhauli Ganga having the Powerhouse Complex located on the left bank of Alkananda river, consists of a number of major underground excavations such as transformer hall, machine hall, APS, CVT. Main Central Thrust (MCT) - a low angle northern dipping tectonic plane is very close to the south of the powerhouse and have been constructed within heavily stressed rock mass.

The TVHPP powerhouse encountered a number of incidences of rock burst during excavation. Various equipment has been deployed in the powerhouse complex as excavation in the Great Himalayan region leads to increasing stress levels under such adverse geological conditions and thus increases the threat of instability in these underground structure and load on supporting structures needs to be observed continuously. NIRM-NTPC authority after the post excavation of powerhouse has decided to install a multi station microseismic monitoring system supplied by the Institute of Mine Seismology (IMS), Australia in the cavern in 2010 to identify the high stress zones, potential unstable areas, propagation of new crack in the rock in the Powerhouse cavern

This paper discusses the installation and primary monitoring results of the first microseismic monitoring instruments in Uttrakhand, India.

\section{SITE DESCRIPTION AND GEOLOGY OF THE TVHPP POWERHOUSE}

TVHPP Powerhouse Complex has a number of major underground excavations with the following dimensions excavated by traditional drill and blast method (TABLE I)

The TVHPP powerhouse area located in the Alkananda valley is situated within rocks grouped as Central Himalayan crystalline rocks, composed mainly of medium to high grade metamorphics. The crystalline rocks of the Dhauliganga valley are derived from pelitic, semipelitic \& psammitic sediments which occasionally are interlayered 
with metabasics. Main Central Thrust (MCT) passes through village Helang located about $2.00 \mathrm{~km}$ downstream of the powerhouse site. TVHPP powerhouse is bounded by a ridge and stream to the north of Shelang village, and Animath naala on the southern side. The area exposes mica schists, quartzite, fine grained quartz mica gneisses and Augen gneisses belongs to Helang formation.

TABle I. MAJor CAVERnS OF POWERHOUSE Site

\begin{tabular}{|c|c|c|c|c|c|c|c|}
\hline \multicolumn{8}{|c|}{ POWERHOUSE CHAMBER } \\
\hline $\begin{array}{l}\begin{array}{l}\text { Len } \\
\text { gth }\end{array} \\
\text { (m) }\end{array}$ & $\begin{array}{l}\text { Width } \\
\text { (m) }\end{array}$ & $\begin{array}{l}\text { Crown } \\
\text { EL (m) }\end{array}$ & $\begin{array}{l}\text { Spring } \\
\text { Level } \\
\text { EL (m) }\end{array}$ & \multicolumn{2}{|c|}{$\begin{array}{l}\text { Service } \\
\text { Bay } \\
\text { (m) }\end{array}$} & $\begin{array}{l}\text { Central } \\
\text { Line of } \\
\text { penstock } \\
\text { (m) }\end{array}$ & \begin{tabular}{|l} 
Branc \\
h \\
TRT \\
Botto \\
m (m)
\end{tabular} \\
\hline $\begin{array}{l}158 . \\
50\end{array}$ & 22.30 & 1314.87 & 1308.12 & \multicolumn{2}{|c|}{1289.00} & $\begin{array}{l}1273.55 \\
\mathrm{~m}\end{array}$ & $\begin{array}{l}1266 . \\
20\end{array}$ \\
\hline \multicolumn{8}{|c|}{ OTHER IMPORTANT CAVERNS } \\
\hline $\begin{array}{l}\text { S. } \\
\text { No. }\end{array}$ & \multicolumn{2}{|l|}{ Tunnel } & $\begin{array}{l}\text { Length } \\
\text { (m) }\end{array}$ & $\begin{array}{l}\text { Widt } \\
\text { h (m) }\end{array}$ & \multicolumn{2}{|c|}{$\begin{array}{l}\text { Crown EL } \\
(\mathrm{m})\end{array}$} & $\begin{array}{l}\text { Floor } \\
\text { EL (m) } \\
\end{array}$ \\
\hline 1 & \multicolumn{2}{|c|}{ Transformer hall } & 147.75 & 18.00 & \multicolumn{2}{|c|}{1316.65} & 1289.00 \\
\hline 2 & \multicolumn{2}{|c|}{$\begin{array}{l}\text { Adit to Pressure } \\
\text { Shaft }\end{array}$} & 245.10 & 6.00 & \multicolumn{2}{|c|}{1281.55} & 1273.55 \\
\hline 3 & \multicolumn{2}{|c|}{$\begin{array}{l}\text { Cable ventilation } \\
\text { Tunnel }\end{array}$} & 289.21 & 6.00 & \multicolumn{2}{|c|}{1306.00} & 1300.00 \\
\hline
\end{tabular}

The rock mass in the area has a foliation trend varying from $\mathrm{N} 70^{\circ} \mathrm{W}-\mathrm{S} 70^{\circ} \mathrm{E}$ to $\mathrm{NW}-\mathrm{SE}$ with dips of $40^{\circ}$ to $60^{\circ}$ towards NE. Based on joints and their spacing, three types of following quartzites has been found above the powerhouse drift: :massive, jointed and highly jointed types. The quarzitic rocks generally strike $\mathrm{N} 70^{\circ} \mathrm{W}-\mathrm{S} 70^{\circ} \mathrm{E}$ and dip at $30^{\circ}-40^{\circ}$ towards $\mathrm{N} 20^{\circ} \mathrm{E}$ direction. The prominent joint sets recorded in the quartzites has been given in "Table. 2 ":

TABLE II. PROMINENT JOIN SETS

\begin{tabular}{|c|l|l|c|}
\hline Joint set & \multicolumn{1}{|c|}{ Attitude } & Spacing & Remarks* \\
\hline S1 & N70-80 ${ }^{\circ} \mathrm{W}-\mathrm{S} 70-80 \mathrm{E}$ & $10-50 \mathrm{~cm}$ & $\mathrm{PR}$ \\
\hline S2 & NW-SE/20-50/SW & $20-50 \mathrm{~cm}$ & PR \\
\hline S3 & NNE-SSW/Vertical & $50-150 \mathrm{~cm}$ & RU \\
\hline \multicolumn{4}{|c}{ (* PR = planar/rough; RU = rough/undulating) } \\
\hline
\end{tabular}

Fig. 1 shows the geological detail of the powerhouse site. A shear zone ( $1 \mathrm{~m}$ thick with $10 \mathrm{~cm}$ gouge) passes in the zone of crown of the powerhouse. Besides the shear zone, there exist bands of biotite schist seams (10-15 cm thick) along the foliation joint (J1) cutting both the powerhouse (between $75 \mathrm{~m}$ to $110 \mathrm{~m}$ chainage) and the transformer hall (between $14 \mathrm{~m}$ to $33 \mathrm{~m}$ chainage). The rock discontinuity characteristics along the powerhouse cavern and three distinct discontinuities, namely S1, S2 and S3 of varying orientation exist along the powerhouse has been shown in "Table.1

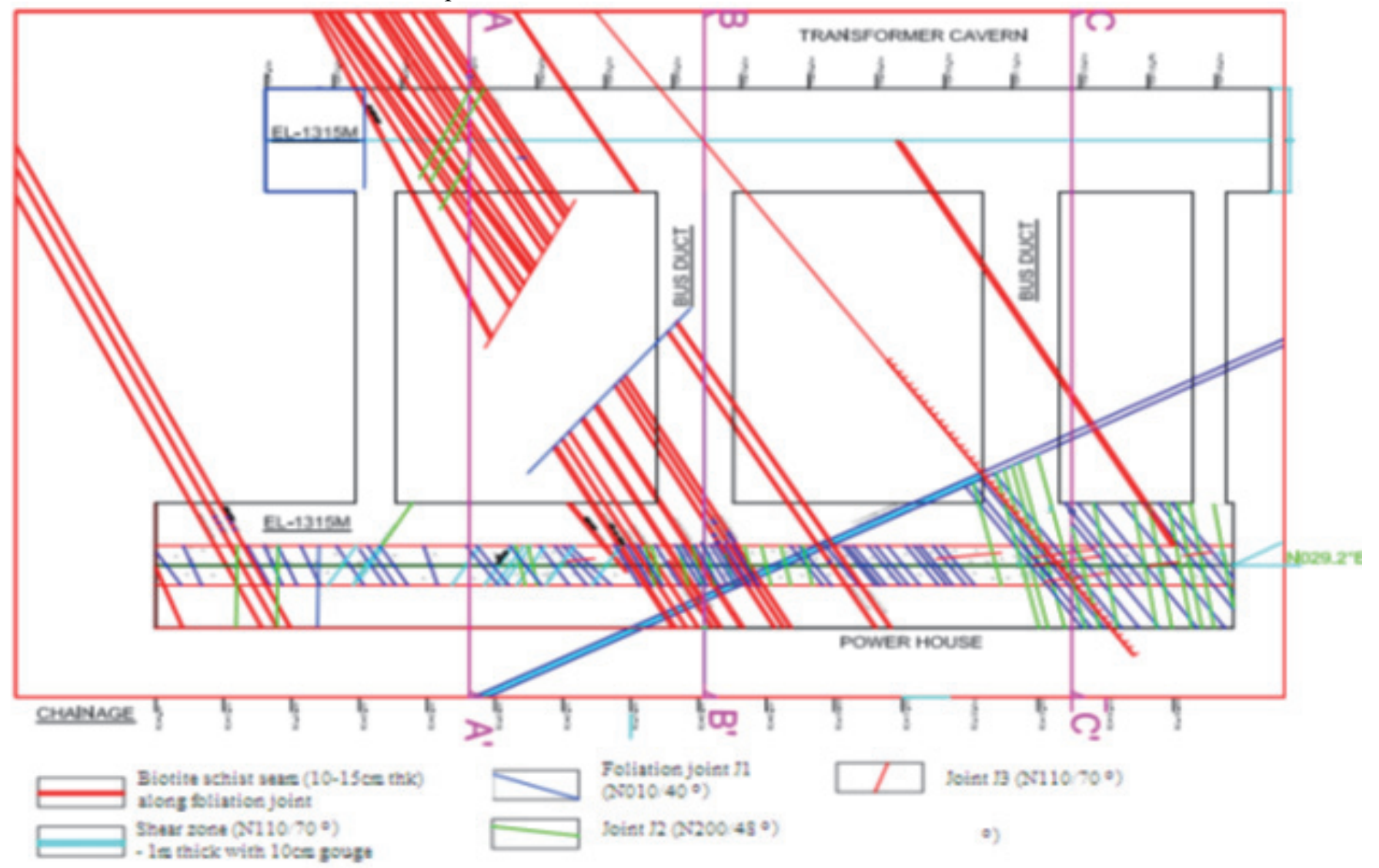

Fig. 1. Geological details of the powerhouse of TVHPP 


\section{ROCKBURSTS AND CRACKS IN THE TVHPP POWERHOUSE}

Cracking and popping sound of rock were heard by persons working in different parts of the powerhouse complex of TVHPP during and after its excavation unit penstocks encountered nineteen rockbursts at various RD's, around SPL and crown level. Cracking and popping in rock in APS and TRT has occurred at RD $252.00 \mathrm{~m}$ in the right side wall above SPL, at end face wall of APS (Adit to pressure shaft) at RD $249.00 \mathrm{~m}$ and right side wall of powerhouse cavern, between RD 140-158 m, EL 1305-1306.

Cracks are propagating in the left wall portion of the powerhouse cavern between EL1312 m and $1305 \mathrm{~m}$. The number and size of cracks is also increasing gradually. The rock formations in this area are quartzite and mica schist band also marked in "Fig.1".

On 13 Sept 2010, a blast was taken for benching activity in the APS that results in rock bursting phenomena on that day intermittently, and but main effect occurred in Unit penstock (UPS) $1 \& 2$. Due to this, steel ribs provided in the UPS-1 and UPS-2 buckled / bent little in the crown portion "Fig 2".

Powerhouse chamber having length $158.80 \mathrm{~m}$ have various cracks and new cracks are also developing in the downstream wall has been shown in "Fig.3".

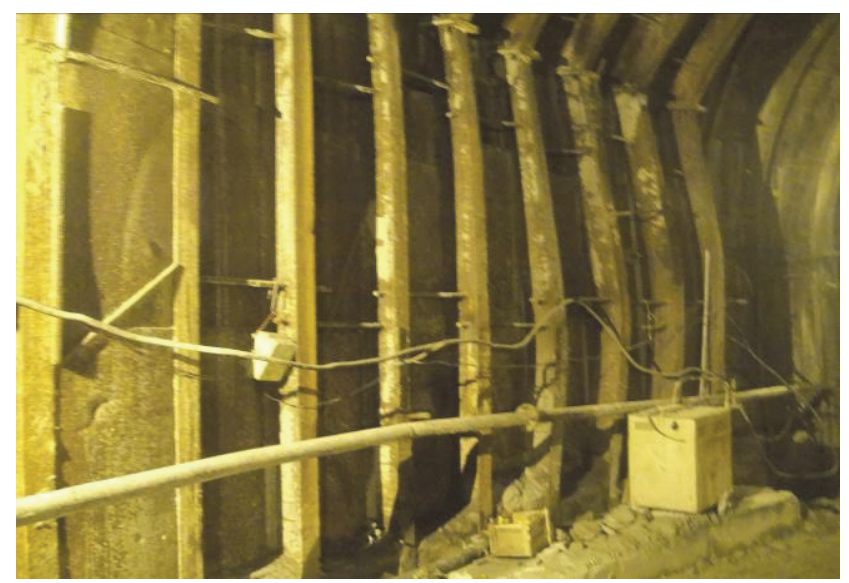

Fig. 2a. Bending of steel ribs in UPS-1

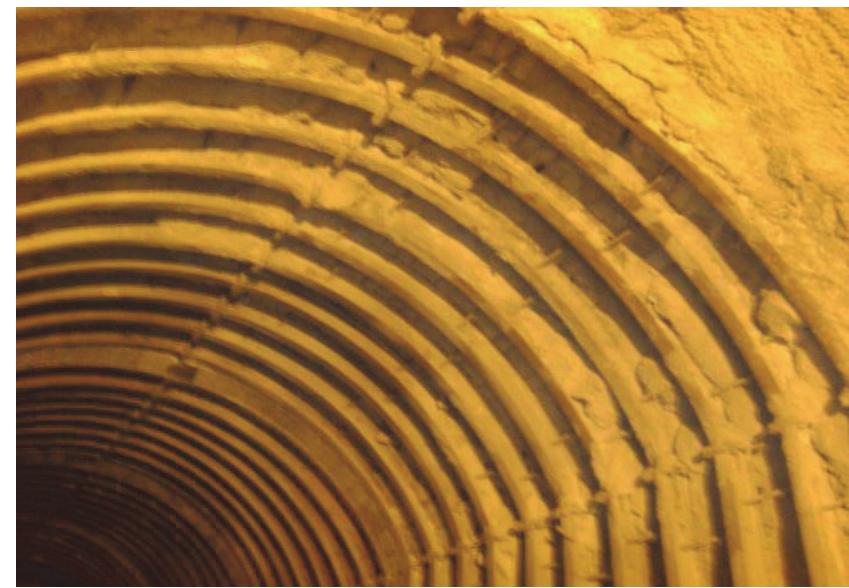

Fig. 2b. Bending of the steel ribs in UPS-2

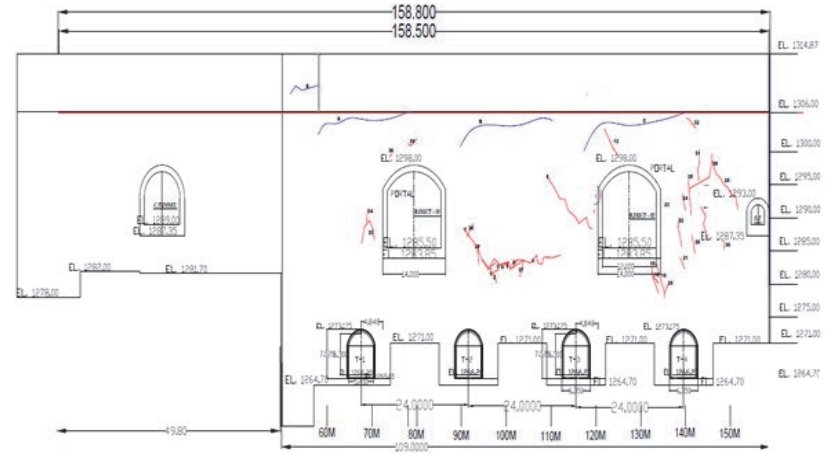

Fig. 3. Cracks in downstream wall of the powerhouse chamber

Four new cracks marked as A, B, C and D (blue color) are propagating and old cracks marked in red has been found between bus duct 1 and 2 and bus duct 2 and escape tunnel EL $1277 \mathrm{~m}$ to $1296 \mathrm{~m}$.

The end wall of the powerhouse cavern has four cracks marked as A, B, C and D as shown in "Fig.4",with the respective length of the crack varies between 4.00 to 16.00 $\mathrm{m}$ and thickness of the crack varies between $15.00 \mathrm{~mm}$ to $100.00 \mathrm{~mm}$.

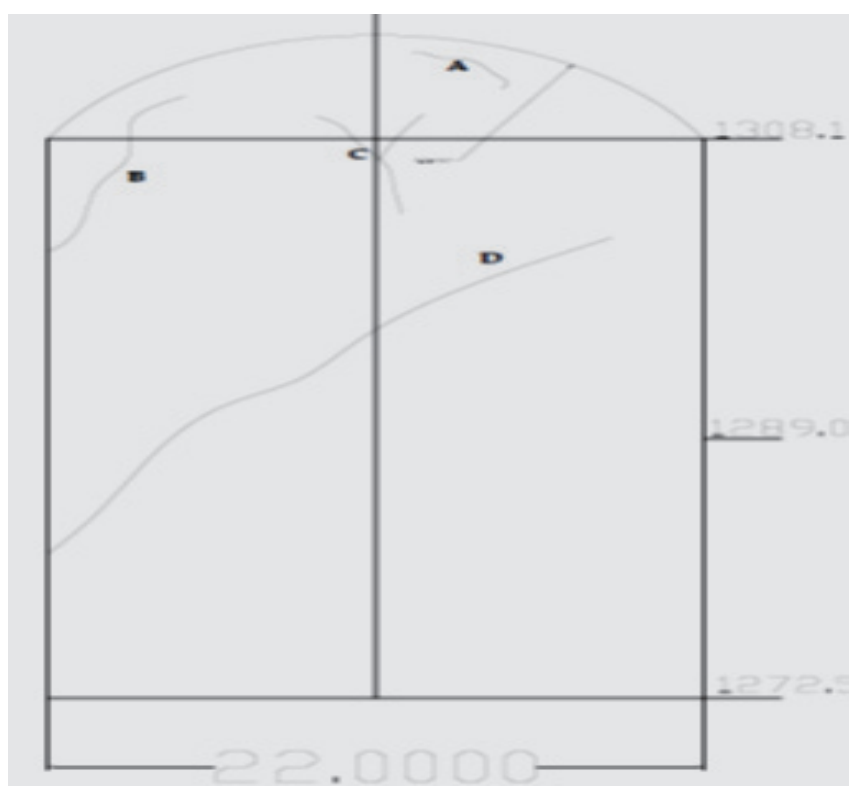

Fig.4. Detail of cracks in end wall of the powerhouse chamber

Cracks in the downstream wall of the Transformer hall has been observed in the crown of the transformer cavern downstream wall between RD $59.00 \mathrm{~m}$ and $72.50 \mathrm{~m}$ at about EL $1308.00 \mathrm{~m}$. Rock mass failure took place between RD $25.00 \mathrm{~m}$ and $35.00 \mathrm{~m}$ and $62.00 \mathrm{~m}$ to $67.00 \mathrm{~m}$.

TABle 2: CRACK Dimension in The END Wall of Machine Hall

\begin{tabular}{|c|c|c|}
\hline Crack No & $\begin{array}{c}\text { Crack Thickness } \\
\text { (in } \text { mm) }\end{array}$ & $\begin{array}{c}\text { Crack Length } \\
\text { (in } \text { m) }\end{array}$ \\
\hline A & $15-22$ & $4-6$ \\
\hline B & $20-25$ & $6-10$ \\
\hline C & $10-20$ & $8-14$ \\
\hline D & $50-100$ & $10-16$ \\
\hline
\end{tabular}




\section{Microseismic Monitoring Method For Post EXCAVATION OF TVHPP POWERHOUSE}

In the underground powerhouse structure, excavation of an enormous volume of rock for longer tunnel in Himalayan region causes stress redistribution as the stresses near the opening are disturbed. The stress redistribution can result in fracture initiation, propagation and rock mass movement along pre-existing planes and such processes emits seismic energy. Hence, excavation induced seismicity can be defined as the rock mass response to deformation and ultimate failure of the rock mass, including the underground structure itself. The areas around the powerhouse, particularly the crown and sidewalls, are prone to unforeseen rockburst and may cause wide spread panic and anxiety among the workforce personnel at the site.

The intrinsic ambiguity associated with the excavated rock cavern of the powerhouse makes it essential to continuously monitor the overall stability.To ensure stability of strata in different zone of underground powerhouse, it is necessary to have a monitoring system which will determine the status of stress concentration zones, and capable to indicate the strata behavior in real time. Such excavation induced seismicity can be studied by using Microseismic monitoring method only. Microseismic method will facilitate timely assessment of instability and identification of high stress zones in the excavated structure. Source location of the microseismic events marks the area in which new fracture starts propagation so that the potential failure zone may be marked in advance [4].

The microseismic monitoring system consists of sensors, data acquisition units, transmission cable, data acquisition, processing and analysis software. By quantification of the seismic response of the rock mass to underground excavation, one can make interpretation in terms of potential failure zone .NIRM Scientists are carrying out continuous monitoring of data recording in the underground laboratory, remote processing and analysis of the data. A basic sketch of the TVHPP microseismic monitoring system has been shown in fig. 5.

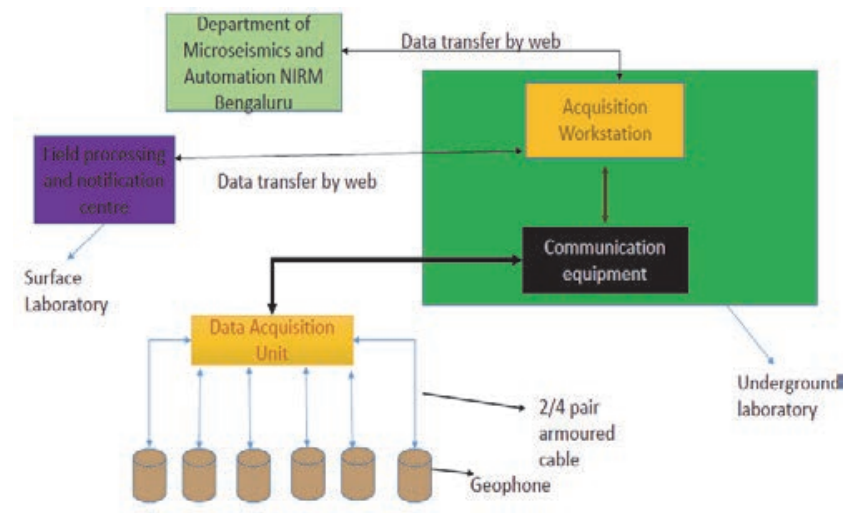

Fig.5. Microseismic monitoring Network layout of TVHPP

\section{Network Designing OF MicRoseISMiC SENSOR}

The schematic diagram 6 shows the geophone network designed based on the reconnaissance survey and $\mathrm{P}$ wave velocity modelling, signal attenuation studies and seismic background noise in June 2011. 30 geophone locations tagged G1 to G30 are marked on the plan of the powerhouse cavern. But the location latter on modified because of the site constraints and inaccessibility of the crown region for drilling.

The decision for type of sensor and its location in and around the powerhouse is the first major step of microseismic application at any site. The choice and position of sensors depends on the following pre survey studies: Geological report (cracks, joints, faults, types of rocks etc.), Rockburst history report, and any seismic velocity report available. The secondary decisive factor in the network is the feasibility for drilling of boreholes and cable layout path, location of DAQ unit, and underground laboratory location (Central server).

Thirty sensors (fifteen uniaxial and fifteen Triaxial) has been installed at the powerhouse site of TVHPP to monitor the different area of the powerhouse site. Two sensors were installed in the UPS 1 and 2 to monitor both the UPS having one uniaxial and other Triaxial. Similarly, two sensors were installed in the UPS 3 and 4 to monitor both the UPS. These areas encountered rockburst that results in the buckling of two numbers of steel ribs in the UPS-2 and three numbers of ribs in the HPS1 in the crown portion, near to fault, popping sound heard earlier.

Five sensors were installed in the APS, having three triaxial and two uniaxial. These sensors not only monitor the APS but also the activity in the upstream wall of the powerhouse chamber. Only one uniaxial sensor (sensor no 28) has been installed due to the site constraints in the upstream wall of powerhouse chamber. Two sensors has been installed in the Adit to Transformer hall (TH) to monitor the adit to $\mathrm{TH}$ and cable shaft as moments has been appeared in the steel ribs in the cable shaft after post construction and adit to transformer has a number of cracks and new cracks are also expected in this zone.

One sensor has been installed at the end of the CVT near to the crown and one more at the junction of CVT and the powerhouse chamber in the crown to monitor the existing cracks in the CVT and opening zone of the powerhouse chamber which has a number of existing cracks and new cracks are also expected. A number of classical instruments has also been installed in this area as this zone suffered a number of rockburst during excavation and still vulnerable. Five sensors were installed in bus duct1. As per the geological report, besides shear zone, there exist bands of biotite schist seams $(10-15 \mathrm{~cm}$ thick) along the foliation joint (J1) as shown in "Fig. 1".There are some old cracks and new cracks also developing around bus duct number 1 as shown in "Fig. 6". Four sensors have been installed in bus duct 2 to monitor the newly develop cracks in and around the bus duct 2.As there is no feasibility to install any sensor at the end wall of the powerhouse chamber, so three sensors will also monitor the accumulation of stress and cracks in the end wall of the powerhouse chamber. Four sensors (15, 24-26) have been installed in the transformer hall to monitor the cracks in transformer cavern crown between RD $59.00 \mathrm{~m}$ 


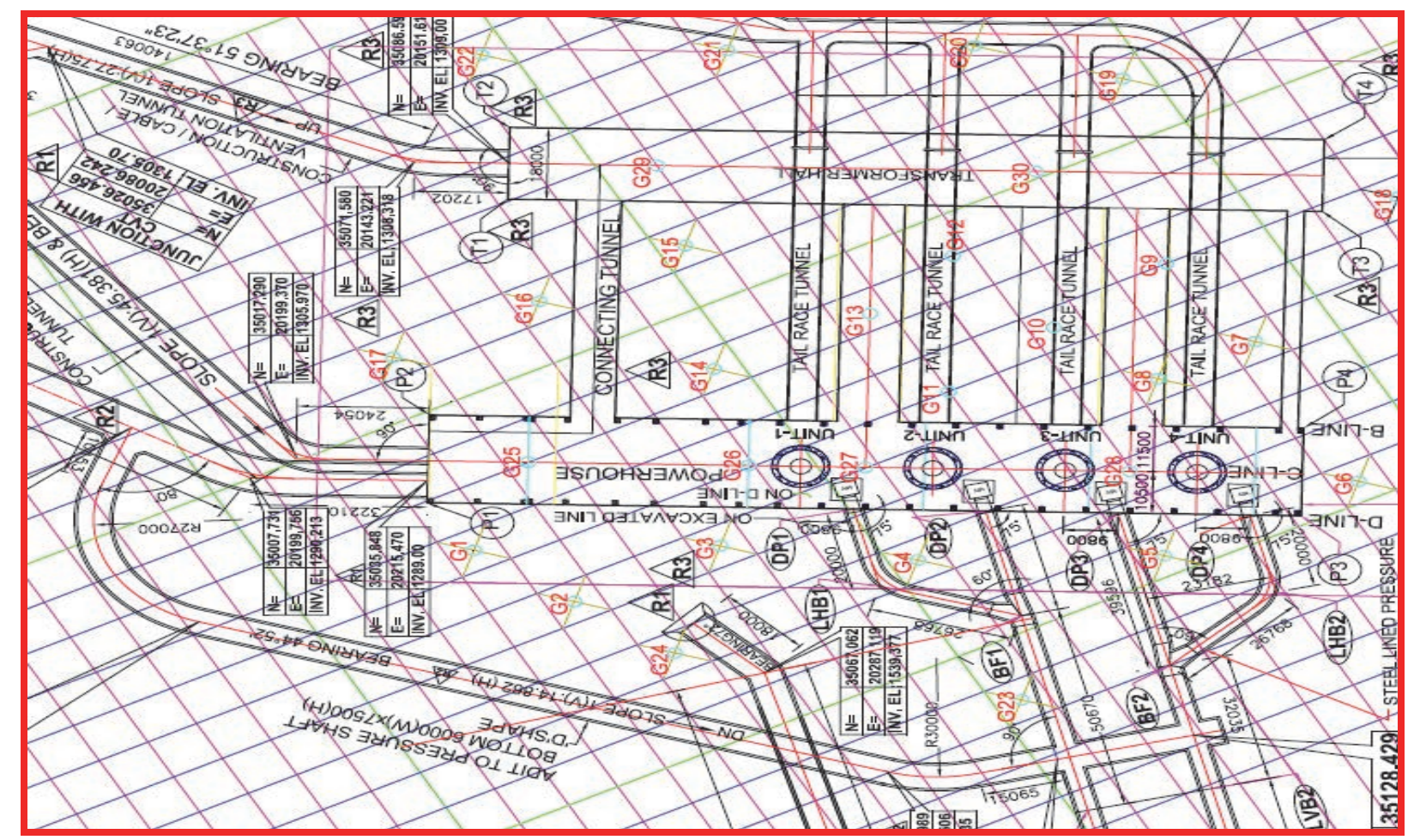

Fig. 6. Geophone network designed after reconnaissance survey

VI. PRIMARY MONITORING RESUltS

to $72.50 \mathrm{~m}$ at about EL $1308.00 \mathrm{~m}$. Earlier rock mass failure took place in the region between RD $25.00 \mathrm{~m}$ to $35.00 \mathrm{~m}$ and $62.00 \mathrm{~m}$ to $67.00 \mathrm{~m}$. There are possibilities of rock mass failure also in the region between RD $10.00 \mathrm{~m}$ to $40.00 \mathrm{~m}$ as this zone consists of mica-schist. Besides shear zone, there exist bands of biotite schist seams $(10-15 \mathrm{~cm}$ thick) along the foliation joint $(\mathrm{J} 1)$ cutting transformer hall between $14 \mathrm{~m}$ to $33 \mathrm{~m}$ chainage. Three sensors have been installed in the connecting tunnel for monitoring the stability of the connecting tunnel as it is an important link connecting both the machine/powerhouse and transformer hall. Sensor number 22 will also monitor the downstream wall of the transformer cavern along with the stability of the connecting tunnel.

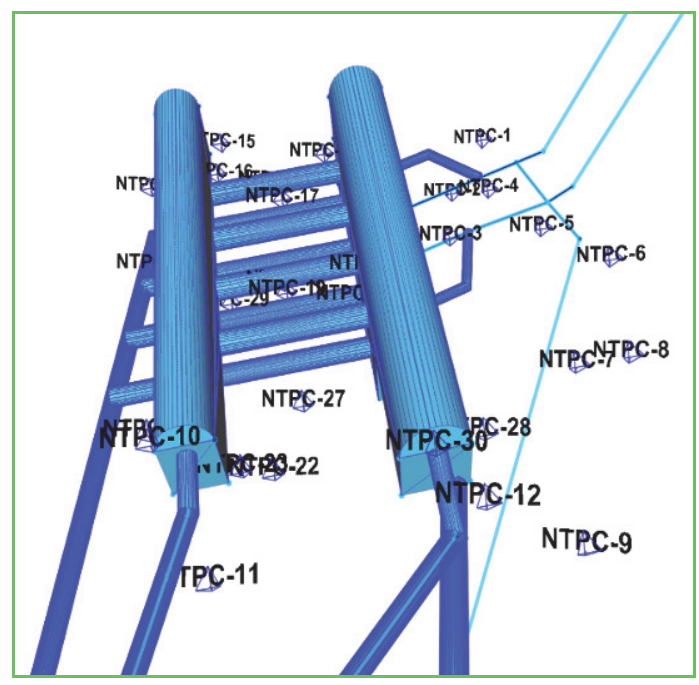

Fig. 7. 3D Visualisation of Geophone at TVHPP powerhouse site
Due to site constraints initially only eight geophones have been installed in the APS and four penstocks which registered about 2000 microseismic events for about six months of data acquisition. The microseismic events are processed using Trace software, one such event has been shown in "Fig.8" along with its source parameters in "Fig. 9". and then plotted on the cavern 3D plan using JDi software shows in "Fig.8".

Five events concentration pockets marked in circle in "Fig.8", gives the potential rock fracture zones in the cavern. "Fig.12", plots the number of events versus magnitude curve which gives the hazard magnitude 1.47. The processed microseismic data has been analysed for the temporal variations of the seismic source parameters to find the stress concentration areas and seismic energy released areas including resultant estimated displacements of different parts of the cavern has been shown in displacement contoured diagram in "Fig. 10".

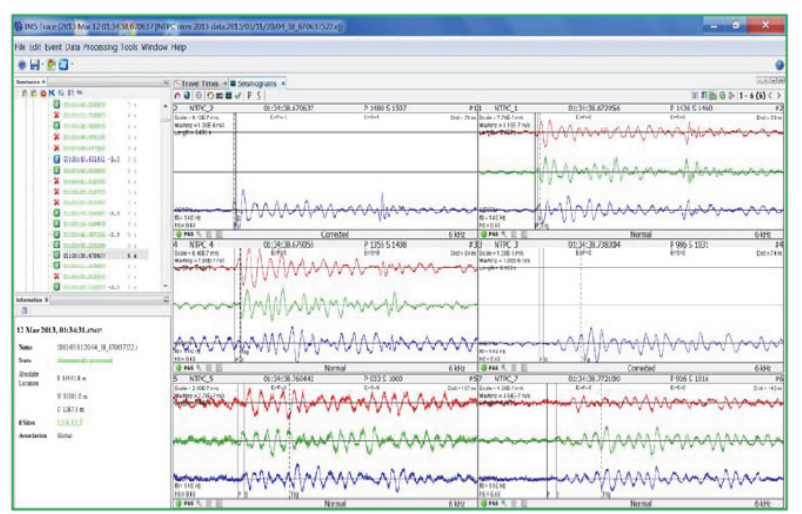

Fig. 8. Typical Microseismic waveform 


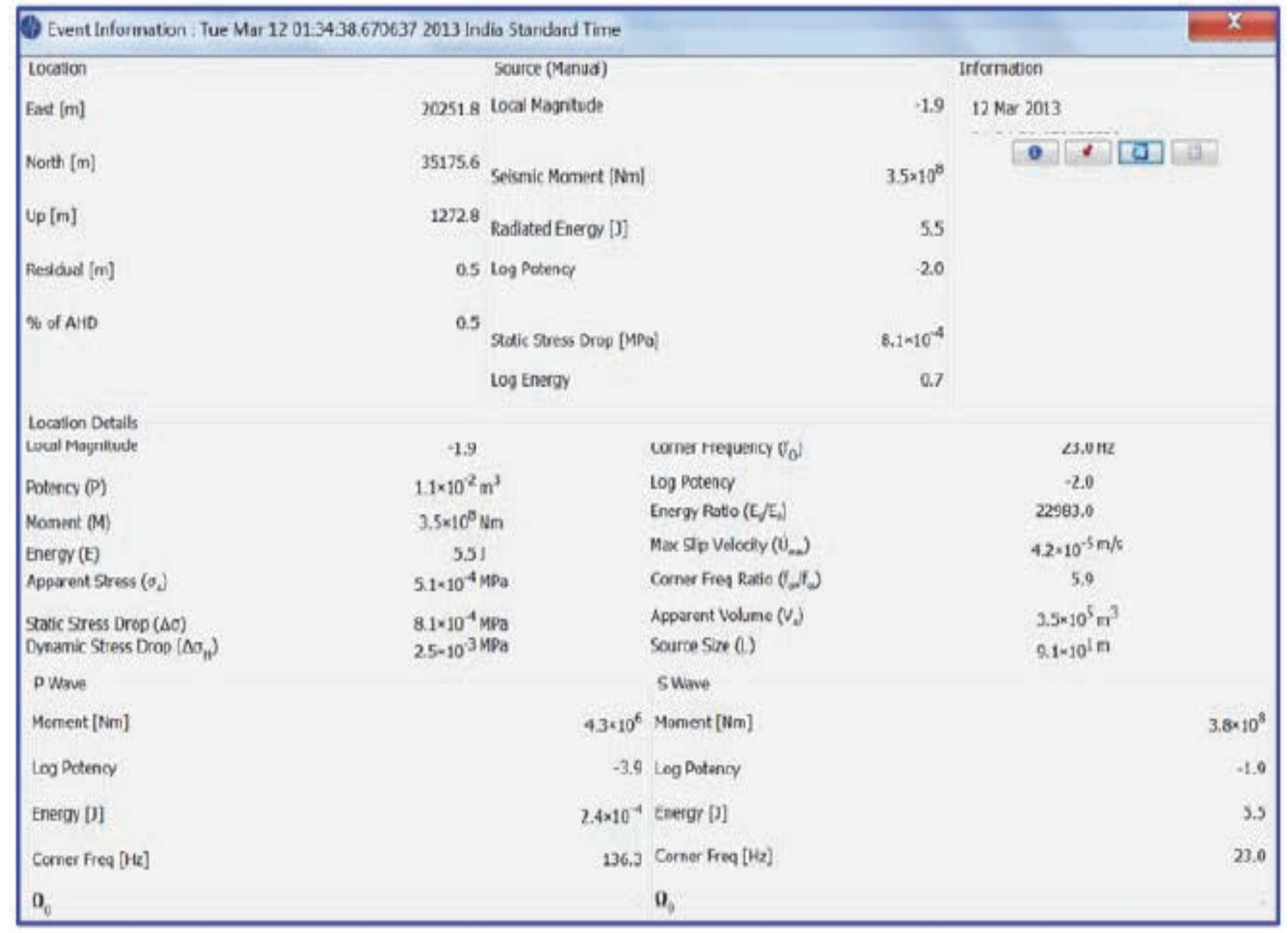

Fig .9. Source Parameters of a Microseismic event

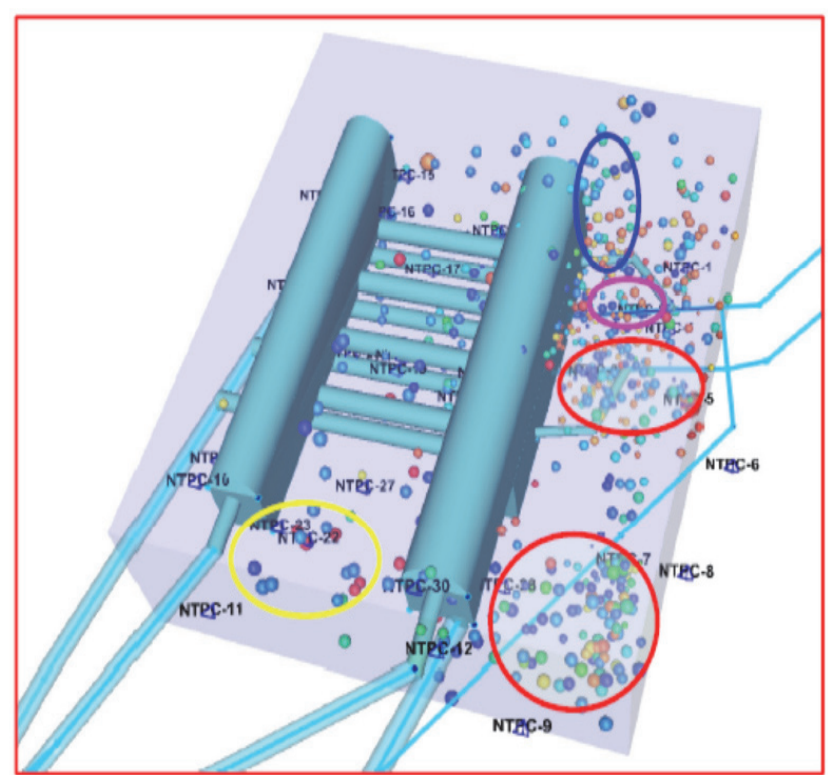

Fig. 10. Microseismic Events

Five events concentration pockets marked in circle in "Fig.10", gives the potential rock fracture zones in the cavern. "Fig.12', plots the number of events versus magnitude curve which gives the hazard magnitude 1.47. The processed microseismic data has been analysed for the temporal variations of the seismic source parameters to find the stress concentration areas and seismic energy released areas including resultant estimated displacements of different parts of the cavern has been shown in displacement contoured diagram in "Fig. 11".

The maximum estimated seismic displacement in the cavern is about $66 \mathrm{~mm}$ at the entrance of the APS and close to the penstock-1 to 2 Junction towards pressure shaft side.

The time series plots of different seismic parameters variations provides valuable information about the status of strata [5]. It is required to record data for a longer period to analyse in detail the status of strata.

\section{CONCLUSIONS}

Major conclusions withdrawn from the primary observations of a microseismic monitoring system installed at the TVHPP powerhouse are as follows: It is the first high precision microseismic network in the Indian Himalayan region to study the stability of the underground powerhouse cavern in an excavated rock mass. 
Installation of the geophone has been attempted on the basis of complex geological conditions with propagation of crack, rockbursts history, and joints

The stress redistribution due to excavation in the different areas of the powerhouse site can be studied and able to demarcate the seismic hazard region using the analysis of microseismic events.

The prediction and deformation of the rockmass in the tunnel can be studied on the number of microseismic events. The present study provides important information about the spatial and temporal distribution microseismic events and an attempt to correlate the microseismic activity induced by the excavation with the stability of the structure.

The study will provide 3-D picture of microcracks distribution and its progress with time, leading to failure that is it will be helpful in determining the long and short term failure in rockmass. With a few definitive failure mechanisms decoded, it will be attempted to incorporate the microcracks in the on-line data processing pattern recognition to forewarn against impending failure and eventually suggest a time-frame to reinforce the affected area to prevent the actual failure.

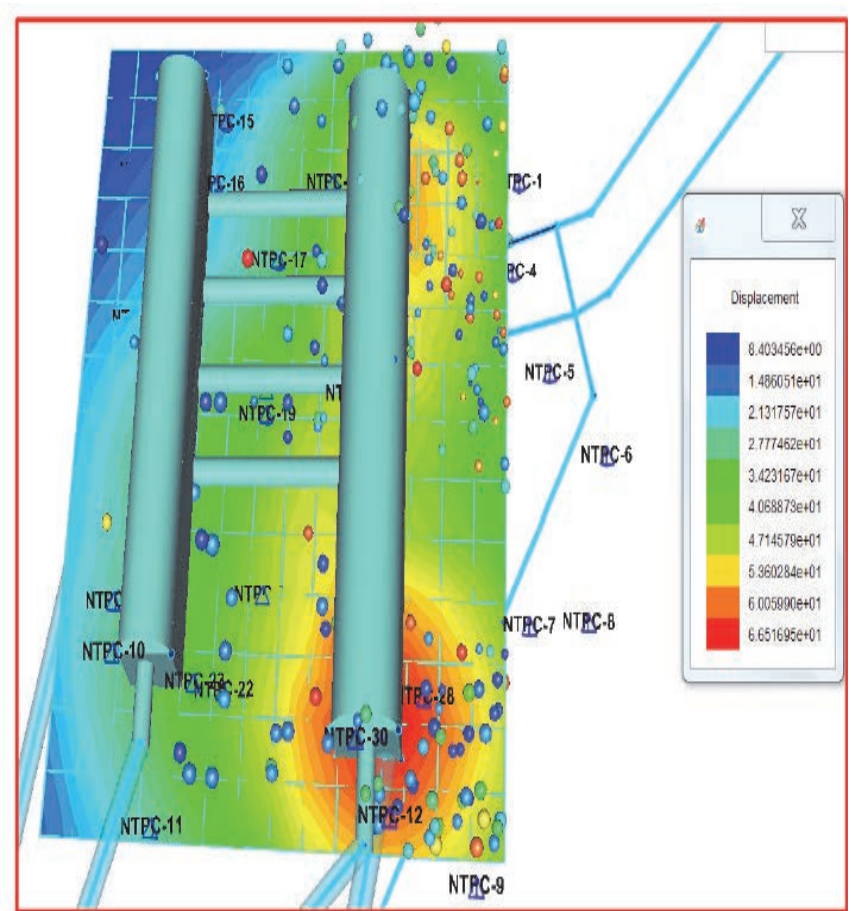

Fig. 11. Displacement contour diagram

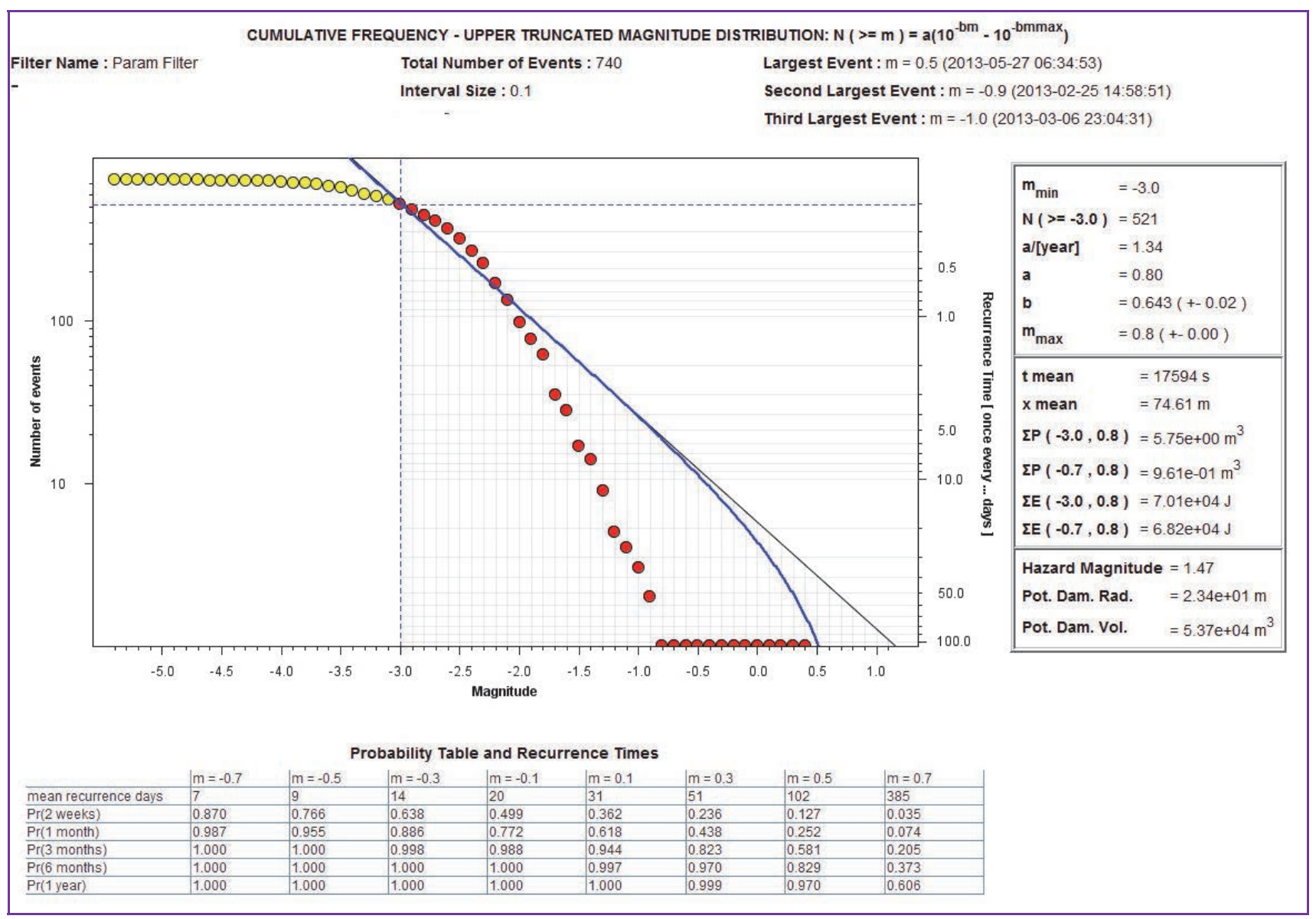

Fig .12. No of events versus magnitude curve 


\section{ACKNOWLEDGEMENTS}

The authors would like to thank the necessary support and permission of the Director, NIRM for this paper. We also acknowledge the financial support of NTPC Ltd. and the Geology, civil electrical and I.T. department of NTPC Ltd. for their co-operation during the installation of microseismic system at TVHPP

\section{REFERENCES}

[1] Bennett, T.J. and McLaughlin, K.L."Seismic Characteristics and mechanism of rockbursts for use in seismic discrimination", in Proceedings of the fourth Symposium on Rockburst and Seismicity in Mines, RASiM4, Poland, 61-66,1997.

[2] Mendecki A.J., "Quantitative seismology and rockmass stability in Seismic Monitoring in Mines", Chapman and Hall, Cambridge, 1997.

[3] T.H. Ma , C.A. Tang , L.X. Tang , W.D. Zhang and L. Wang ,"Rockburst characteristics and microseismic monitoring of deepburied tunnels for Jinping II Hydropower Station", Tunnelling and Underground Space Technology, 49 , 345-368,2015.

[4] Lynch R.A, Mendecki A. J., "High-Resolution seismic monitoring in mines", Proceedings of the 6th Symposium on Rockburst and seismicity in mines (RASIM5).

[5] Chun A. T., Wang J. and Zhang J., "Preliminary engineering application of microseismic monitoring technique to rock burst prediction in tunneling of Jinping II project", Journal of Rock Mechanics and Geotechnical Engineering, 2 (3): 193-20,2010 